\title{
Pedagogical Recognition
}

Raquel Ayala Carabajo, Universidad Católica de Santiago de Guayaquil (Ecuador) Email: raquelayalac@gmail.com

\section{Abstract}

Pedagogical activity, be it of parents or teachers, continuously requires us to meet children's and youngsters' deep ethical needs. In our daily relationships with them, recognition is one of the most frequent and essential ingredients of our educational activity. But, what does being recognized mean? When does this everyday practice become genuinely pedagogical?

This phenomenological inquiry explores pedagogical recognition, an experience of an essentially ethical sense. Through our words, actions, decisions, etc., we offer children and young people effective learning experiences about what is good and right in our human world. Moreover, genuine recognition allows us to discover the personal worth and uniqueness of every child and young person entrusted to us. Recognition deals with the very being of people revealed through their capabilities in action.

In this experience, the educator plays the decisive role. ${ }^{1}$ Thanks to our pedagogical responsibility and influence, we have the power to recognize; a power that has been given to us by the child and that can be observed when the transformational effect of recognition occurs. Pedagogical authority is the foundation of recognition as well as educational intentionality. The pedagogical significance of this practice requires every educator to evaluate and to improve the ways of doing this effectively, especially by thinking carefully about every person's singularity and by developing awareness of our ethical personality and our embodied language. It may lead us to being recognition.

\section{Introduction}

Marie is attending her first painting class and it makes her happy. Pictures, paintbrushes, models... Could it be a good pretext to engage in dialogue? Perhaps. I hoped this experience would strengthen our relationship.

Now, she is asking me to look at what she has painted. In the middle of a colorful mixture of paint boxes, leaves, flowers, pencils, etc., she has placed her pictures. The first one is a nice composition of natural elements on cardboard. It is a good reproduction. I take the cardboard and tell her warmly: "You have done very well! It is a nice picture!" She looks pleased and points out her latest paintings: "I've learnt a lot!" she says. She has many future projects. I perceive the enthusiastic tone of this little dreamer. 
We are really enjoying this special interchange of perceptions, tastes, and techniques. I feel a comforting atmosphere between us. Here is another of her paintings. She likes it a lot. I agree with her that it is "the best" (However, I do not really have any preference, but I feel I should agree with her choice...). I point out one detail that shows how skilful she is now with watercolors: this, the flower's shadow looks very natural. She nods and smiles. (A personal experience as a painting teacher)

This was the first time that I had felt so close and comfortable when recognizing Marie's artistic work. Once again, I asked myself some persistent questions: Why did I feel like this? Were my feelings related to her personal satisfaction? Was my recognition appropriate because she was feeling personally recognized? Does recognition by an educator depend on the student's perception of his or her work? These were some of the questions that led me to explore the notion of recognition further.

We may sometimes feel uncertain about the suitability of the recognition that we offer in some pedagogical situations. Certainly, recognition is one of the most common gestures in our pedagogical lives as parents and teachers. "Mom, look at what a big castle I've made with the blocks!”; "Dad, do you like my picture? This is a portrait of mom!”; "Good, darling! Thanks for tidying up this room"; "This is the best composition I've received this week! Congratulations!”...These are a few manifestations of this everyday phenomenon. In addition, "giving encouragement and positive feedback is one of the most common gestures expected from teachers in classrooms" (van Manen, 2002a, p. 35). Spontaneously, recognition is almost continuously sought from teachers in any classroom anywhere. Likewise, this is something given almost continuously by teachers. Think of a class-full of five-year-old children: one child improves in reading, another makes a noticeable gesture of collaboration, a little girl manages to learn a poem by heart. All instances calling for recognition.

However, gestures of everyday recognition, while so easy to give and to receive, provoke significant questions: What does being recognized mean? What does giving recognition mean? What are the conditions for pedagogical recognition?

\section{The Project}

Led by these questions, I carried out a hermeneutic phenomenological study (Ayala, 2008) inspired by van Manen's approach (van Manen, 1997). Recognition is a notion and a phenomenon studied in different ambits of knowledge from politics to ethics (Connolly, 2007). My objective was to explore the phenomenon of pedagogical recognition, that is to say, the experience lived in the context of a pedagogical relationship. The aim of this project is "to uncover and describe the structures, the internal meaning structures, of lived experience” (van Manen, 1997, p. 10) and of recognition in a pedagogical context, acknowledging that:

pedagogy requires a phenomenological sensitivity to lived experience (children's realities and lifeworlds). Pedagogy requires a hermeneutic ability to make interpretative sense of the phenomena of the lifeworld in order to see the pedagogic significance of situations and relations of living with children. And pedagogy requires a way with language in order to allow the research process of textual reflection to contribute to one's pedagogic thoughtfulness and tact. (van Manen, 1997, p. 2) 
In the spring of 2007, the experiential dimension of pedagogical recognition was pursued through accounts written or told by four selected teachers. These teachers were chosen because of their tendency to be attentive to the subtle signs of everyday events lived with their students. Their Lived-Experience Descriptions (LEDs) have been the basic material of this inquiry, which integrated these original descriptions and the experiential material gathered in interviews with the participant teachers. The result was expanded anecdotes or synecdotes, as Henriksson (2008, p. 6) calls this modality of edited description. In the included synecdotes, I am using the same words that the teachers used to express the meaning of their experience, trying to faithfully reflect the pathic content transmitted during the conversation.

As van Manen (1997) states, anecdotes are a methodological device with an important place in hermeneutic phenomenological inquiry. They are capable of acting and mediating between the particularity of an experience and the universality of its meaning. Anecdotal writings make it possible to apprehend and to disclose some elusive meanings. This study is focused on the lived dimension of recognition and not on its theoretical conception, since anecdotes prevent one from falling victim to an abstractive tendency. Every anecdote is a probable story. It is a probable story for us. It means that each one of us could experience every anecdotal story. In this sense, the anecdote may constitute potential material for experiential learning, as well as a subtle recommendation to act with tact. A compelling anecdote "simultaneously pulls us in but then prompts us to reflect” (p. 121). At the same time, it lends us the ability to grasp reflective and pre-reflective dimensions of knowledge. In consequence, it provokes the establishment of the relation between theory and life.

After this first period of gaining experiential material, thematic reflection (performed as macro-thematic and micro-thematic reflection) was then developed. As a result of this work, various phenomenological themes emerged. They were examined for essential elements of the phenomenon of recognition. Thanks to the method of variation in imagination, the incidental meanings were eliminated. At this hermeneutic or interpretative stage, the reductive attitude (van Manen, 2002b) — hermeneutic, phenomenological, eidetic, etc.—was a critical aspect. For example, hermeneutical reduction was used to make explicit, to bracket and to discuss some personal presuppositions and some "taken-for-granted" ideas about recognition (see in Ayala 2008 practical examples of this process). Later, the resultant phenomenological text was contrasted with two contributions by van Manen (1996, 2002a) about pedagogical recognition and one by Ricoeur (2005) about human recognition.

In addition to the teacher's anecdotes, experiential accounts from three other sources have been used in this study. First, from my personal experiences of recognition; second, from selected autobiographical texts by Edith Stein, who was a doctoral student of Husserl's and also his first assistant; and, third, from the French documentary Etre et Avoir (Sandoz, 2002). ${ }^{2}$ Based on these sources, this paper is going to explore some essential meanings of pedagogical recognition as well as its pedagogical importance.

\section{“Look at this! ...Look at me!”}

The teacher is sitting at a little table with a small group of children who are learning to write the word "mom." There is a peaceful mood. Every child is working on his or her own sheet of paper, but they are sitting together at the same little 
round table. The teacher is seated between two girls and helps one of them. He takes her marker and guides her strokes.

Their activity is intense; the markers slide insecurely on the sheet. The teacher has written a model of the word on every child's sheet. They are trying to copy it. All of them continuously seek approving looks from the teacher and verbally ask for his attention. The teacher seems fully immersed in the handwriting activity and goes from one child's work to another offering thoughtful attention and words. The teacher's face expresses concentration. The children also seem applied to the task. This attitude of total implication from the teacher offers the sensation that learning to write is an "important thing."

- "First, do it up to here," the teacher explains to Alizé. At the same time, Jojo is trying to write the first word...The teacher takes Jojo's hand (with his marker) and explains to him how he should write:

- "Jojo: start here and move downwards to here..."

- "Yeeeeeeeesssss, I already know how to write this word!" answers Jojo and takes his marker out of the teacher's hand to continue writing.

- "Sir," "Sir," "Sir," some voices call.

- "Yes, that is very good Létitia. Keep on... But here you have forgotten to go up to the point. Go up a little more!"

- "No, Johann, no; you should turn the sheet, turn it...Turn it, please."

- "Sir... should I make a circle here?"

- "Yes, that's right: a circle. You should go up a little more. You've forgotten to go back up. Go up to there... Stop. And now, start from here to make the circle."

After a few seconds of writing, Jojo remains thoughtful and looks at his teacher: he doesn't know how to continue... Instead of asking, he continues, but after a few strokes, stops and thoughtfully looks at the rest of the children and listens to his teacher's words. Then he indecisively says to his teacher: - "Sir, I haven't understood it very well..." While this occurs, the teacher continues guiding little Alizé's hand and another girl calls him, reaching out to his arm.

- "Sir, Sir, I have already finished," says one child.

- "Sir," "Sir," "Sir" (The children's whispering voices try to attract the teacher's attention).

- "Look at this, Sir!" Marie says to him and almost at the same instant other voices say the same. Immediately, Létitia says to him, "Sir, look!" while shyly reaching out her hand to touch the teacher and to attract his attention.

The teacher examines Marie's handwriting and says to her with conviction:

- “Ah! Very good, Marie!” and then he says to Létitia, "Yes, that's very good Létitia. Look: start here and go up to here...”...He encourages Létitia, but in a very different tone (...). (A scene from Être et Avoir, 2002).

Immersed in the stream of daily events, a teacher may not be aware of the calls for recognition made by every child. In this scene, minute by minute, the word "mom" takes a written form while this intense pedagogical situation occurs: "Sir," "Sir," "Sir..." call the children, and "Yes, this is very good"; "No, Johann, no. You should turn the sheet, turn it”; "Yes, that's right," "Ah, very good!" the teacher answers. Recognition seems to be a basic human need and so it is not difficult to recognize the children's constant striving for recognition.

Effectively, considering closely and carefully the relations maintained with children and 
young people, it is easy to discover this active and subtle desire to be recognized. Nevertheless, sometimes it can be hidden under the appearance of affective necessity. For example, John requests affective answers from me permanently, making me feel that he has a lack of parental affection; Wendy, who anxiously wants me to share her opinion, makes me think that I am dealing with an immature personality; I interpret Janet's strange behavior as a strategy to attract my attention, etc. Sometimes, I could feel hurt when I think that a beloved person misunderstands or does not know who I am. I could interpret it as a situation of low self-esteem or affective dependency on this person. Nevertheless, all these experiences may simply be forms of manifestation of a desire to be recognized. Surpass this superficial facade and you will understand that this desire goes beyond the affective domain.

By considering the etymological meaning of the word recognition, we discover that every call for recognition is a call to "return" to a person, as it were, a request to be noticed. The verb "to recognize" comes from the Latin recognoscere, which translates as to "acknowledge, recall to mind, know again, examine, certify," and which breaks down into re- ("again") and cognoscere ("know"), which in turn breaks down into co- ("with") and gnoscere ("become acquainted"). The basic meaning of "to recognize" is to "perceive something or someone as already known." 3 If recognition means to "know someone again," how can that be accomplished? Is it possible to know someone again if we know him or her already? In what sense can this be done? I underwent an experience as a trainee-teacher that helped me glimpse this possibility.

\section{Being Recognized}

We are arriving at the hall. Rose is waiting for us. She is the principal of this little school and, at the same time, teaches four-year-old children. She will be my supervisor for three months. This is my first day of work.

She welcomes the children and me in a special way: She puts her hands on each of our faces and kisses us on the cheek after interpreting our facial expression. This is not a common gesture! I feel it's a bit "strange." "Why? You have not met me before!" I think. Nevertheless, she does it gently, as if everyone were a very special person for her. Now, I feel that I am entering into a new dimension of relationship. I contemplate what happens with the children who wait to enter. It is wonderful to be a witness! She is full of enthusiasm and consideration. Every child is received in a personal way: "How are you, Steve? Are you happy today? How is your little sister? I am happy because you are here!" And Steve smiles. The next in line receives another kind of greeting, but enthusiasm and sincerity are maintained. (A personal experience as a trainee-teacher)

She has impressed me immensely. Why did she welcome us in this way? How did she keep up that way of recognizing her children's performance? Every day with every child! I did not think she was "playing a role" because I certainly felt myself to be a "unique" and important person. When I remember my relationship with this teacher, I feel certain that this experience was one of the key experiences of my life in acquiring a clear and positive view of myself. I felt confidence in my first teaching experiences. I felt appreciated. Furthermore, I got a glimpse of my potential possibilities as a person and as a future teacher. How does she do all this? Was it the tone of her 
voice? Perhaps. Was it her way of enjoying our presence? I do not know. She was very attentive and open to everyone and these attitudes were especially revealed in situations of welcoming and of recognition (which I remember as intertwined).

Thanks to this teacher, the nature of recognition was disclosed to me in a profound way. I felt that recognition, "above all, means welcoming the other person as Thou, that is to say, not empty-handed. The spirit is not the Said, it is the Saying which goes from the Same to the Other, without suppressing the difference” (Levinas, 2006, p. 55). I felt free to be myself with her; she was always willing to welcome me. She did not suppress my difference; she appreciated it.

My experience was one of being considered from a new perspective: I was a person. It might be strange to speak about being seen "as a person": I am a person! Yes, but in our real life this could be an unusual experience. I might be seen as someone who "works," "makes," "gives," "seems," "knows," and so on. But, this teacher gave me the opportunity to understand what "being recognized" means. In fact, before I had done "something worthy of recognition" I had received recognition. In this situation I felt that what was being recognized was myself as a person. This teacher had the ability to offer me this experience. I felt that "someone who recognizes me thereby acknowledges my existence, my very being... Recognition is inextricably intertwined with self hood and personal identity” (van Manen, 2002a, p. 38).

Actually, the core of being recognized is to be recognized for our being. What $I$ am is the worthiest thing that I hope and wish that you recognize. When you recognize what I do, what I say, what I have, it is just the beginning. When you recognise who I am, the unique person I am, you re-know me in the deepest form. You give me the main thing that I need, the main thing that I deserve: being recognized in my being.

In this sense, recognition is a great opportunity to deal with the uniqueness of children/young people. At the same time, it is a great responsibility. To take care of the uniqueness of the other is pedagogical love. Levinas (2006) sees a profound relation between uniqueness and love: "the relationship goes to the unassimilable, incomparable other, to the irreducible other, the unique other. Only the unique is absolutely other. But the uniqueness of the unique is the uniqueness of the beloved. The uniqueness of the unique signifies in love” (p. 167).

\section{Learning to Recognize Genuine Pedagogical Recognition}

\section{Recognition, Mis-recognition, Non-recognition and Praise}

Recognition is a powerful factor of human existence (van Manen, 1996). A great many of our actions depend on the possibility of gaining recognition. Ricoeur (2005) offers philosophical ways to explore essential meanings of human recognition. His departure point is the intriguing polysemy of the word recognition. Its variety and amplitude of meaning revolve around three main concepts: ${ }^{4}$ to apprehend something mentally or to know something or someone because you have seen or experienced them before; to accept that something is true or real; and to thank someone for something good that they have done. The French philosopher indicates that the first meaning precedes to the next in the philosophical study that has been developed (op. cit). Actually, each dimension of recognition depends on the previous one. Thus, in the meaning of the word, a continuity occurs from the identification to the recognition of objects or people. Ricoeur emphasizes that this route is reflected in the passage of the active voice (to recognize) to the passive (to be recognized). Ricoeur's contribution is a phenomenology of human recognition 
that begins with cognitive identification and becomes recognition of oneself (personal capabilities) advancing towards mutual recognition, the third level of recognition. Selfrecognition is always in tension with mutual recognition; a struggle to overcome misrecognition in the eyes of others.

Pedagogical recognition could be considered as a modality of the mutual recognition proposed by Ricoeur. It is the recognition as offered by and demanded of an educator. Although it is offered by others, it is not essentially mutual recognition: the pedagogical relationship is asymmetric (van Manen, 1998) and, in my opinion, this feature restricts reciprocity.

Ricoeur describes the recognition of oneself as a testification: recognition of oneself as a person capable of doing, of saying, of constructing, and of narrating their own identity. Consequently, to be recognized by somebody, whenever this occurs, would mean receiving a guarantee of one's identity. However, giving and receiving recognition is, essentially, a struggle. We are always trying to avoid misrecognition and to gain recognition. This is a hard task that is always unfinished.

Not recognizing a child or youngster is to deny them this knowledge of their personal capabilities and possibilities. It means forming an erroneous or false idea about their capabilities and identity, i.e. misrecognizing them. When this non-identification and non-testification is extreme, it becomes non-recognition. This may happen when an adult passively omits recognition or explicitly disregards a student, leading to genuine scorn.

Basically, recognition has a positive sense. For that reason a prefix is needed to indicate its defect (mis-) or its absolute negation (non-). Effectively, to recognize (to identify the reality, to distinguish between false and true, to admit a responsibility, to appreciate, etc.) is a positive action. This is the experiential sense despite the fact that recognition may be of personal limitations. It is clear that to know one's own limitations is an advantage. The problem lies in the use of this knowledge. To know someone (that is, someone's limitations) in a non-pedagogical sense is a negative practice of recognition (Henriksson, 2008).

Besides, recognition can take the concrete form of praise. Praise is "the act of expressing approval or admiration; commendation; laudation” (Dictionary.com). Praising is always verbal. Praise and recognition are two experiences that do not coincide necessarily since it is possible to recognize without praising, as well as to praise without recognizing. Indeed, while recognition is a central experience in pedagogy, praise is one practice among other possibilities. For example, it is possible to recognize by smiling or giving a warm gesture of approval; a good mark or the concession of a special responsibility could also be recognizing actions. It is even possible to recognize verbally without praising: "Mary has a good memory," "Frank is capable of intensive intellectual effort," "Michelle has a gift for drawing," etc. are verbal expressions that reveal personal qualities but without laudation. Sometimes this form of objective verbal recognition is better received than praising. This is the case with teenagers. At the same time, praising is an action typical in mutual recognition: we do not praise ourselves usually. On the contrary, recognition from others assumes self-recognition.

Saeverot (2008) describes praise as positive reinforcement of desired behaviours that are postulated in advance. The praise clearly shows what the adult appreciates. In my opinion, the strong affective ingredient with which this praise is expressed reinforces it. Therefore, a great influence is exerted on the ethical personality of children and youngsters, which is not necessarily positive in a pedagogical sense. As Saeverot points out, praise can be employed in a conductist way. In this case, it could lead students to adopt forms of thinking according to the curricular requirements, moving away from the possibility of developing independent thinking. On the contrary, when praise is a manifestation of pedagogical recognition it acquires all its 
significance, especially with respect to the configuration of the student's ethical personality.

Moreover, whereas praise cannot be used indiscriminately (neither to everybody nor all the time), recognition is a pedagogical responsibility. At the same time, praising can be extremely easy, whereas to recognize and to be recognized are extremely difficult. As Ricoeur (2005) affirms, it is in essence an endless battle. The reason is that an "originary asymmetry in the relation between self and others" exists (p. 261). Likewise, whereas it is not absolutely necessary for us to be praised, we really need to be recognized by our own selves and by others. These two levels of recognition are based on the previous forms of recognition: identification of things/people, and the distinction between true and false. In contrast, praising does not have this implicit reference of truly acknowledging a person, so to speak. Rather, its underlying reference is the world of values of the adult who praises. To praise out of the context of recognition is not testification of what a child or young person is able to do or to be, but the testification of what an educator considers valuable or worthy.

\section{The Actors of Recognition}

On my way to university, I could not get my head around the matter of "empathy"... I had been reading book after book, and making extensive summaries of them. But he more material I found, the more confused I became... My struggle in pursuit of clarity was bringing me a lot of pain, and I could not relax either by day or by night.... I was getting more and more desperate. It was the first time in my life that I had come across something that was impossible to reach through my own will... This situation became so serious that my life seemed unbearable.

Then, I had an appointment with Reinach... I took my rough copy, which I wanted Reinach to keep and read. To my surprise, he asked me to stay: he wanted to read it immediately. He gave me a copy of Hegel's "Phenomenology of Spirit," which he had on the table. I opened the book and tried to read some of it, but it was hard to concentrate. It was so touching to be seated there while my "judge" was trying to form an opinion of my work. He read carefully and occasionally nodded his head in approval, from time to time making sounds of agreement. He read it amazingly quickly. "Very good, Miss Stein," he said. Was it possible? He did not really have any objections, and insisted that I should not stop working... The holidays began and Göttingen started emptying. I was left alone in my little room sitting at my desk. As I had no classes, I could write without interruption. I had finished in a week...

The next morning, I took my manuscript there and knocked at his door. Reinach himself answered it... This time, I was not as anxious as I had been before. Reinach was very satisfied. I asked him whether the work would be good enough for the state exam. "Sure. Husserl will be very pleased, because he doesn't receive work like this very often." Now I could enjoy my vacations without having to worry about it. We happily said our goodbyes until April.

After those two visits to Reinach I felt like I had been born again. All the weariness had gone from my life. It was if my guardian angel had saved me from danger. It was as if a magic word had transmuted all the monstrous freaks in my poor head into a clearly coordinated order. I had no doubts that I could trust his judgement. Calm, I put the work to one side, to instead put all of my effort into 
preparing for the oral exam. ("Vivimos para servir. La juventud de Edith Stein," 2005, pp. 137-139)

In this scene from Edith Stein's youth, we understand that the figure of the professor constitutes the core of her recognition experience. The same words, "Very good, Miss Stein" could not have had the same meaningful effect upon her and her work if they had come from another person. Nevertheless, Reinach was her professor, and a professor in whom she had a great deal of trust. ${ }^{5}$ As in this past experience, in experiences of pedagogical recognition, the essential actors are always an adult and a child or young person being recognized. Furthermore, this young person and this adult must be linked to each other by the unique and strong bond of a pedagogical relationship. It is always the educator who recognizes - thanks to their influence on the person, to their affective relationship with him or her, to the trust he or she inspires, and/or to the authority that he or she possesses. The recognition that we remember most, we appreciated most, and that which has left a mark on us is recognition given to us by a meaningful educator.

However, classroom experiences of recognition are usually made in public. How does this fact determine the experience of recognition? Van Manen (2002a) states that "recognition, and the feeling it produces - a positive sense of self - are public phenomena" (p. 38). Nevertheless, this phenomenon, though normally experienced in "public", is not essentially public. In other words, the presence of "others" apart from the educator is not essential. In the earlier descriptions, in the personal experiences, or the experiences witnessed by us, we could try the imaginary elimination of other people's presence and verify that the integrity of recognition persists.

So, what is the difference between a public and a private experience of recognition? What is the function of "the public" in pedagogical recognition? It seems that while the essence of recognition is not affected by the presence of a public dimension, the way of living this recognition varies. Normally, it is easy to admit the fact that "the compliment is strongly felt when it is conferred in public, in the presence of others. Why? The others are implicated or witness to the feeling of pride that follows from praise" (van Manen, 2002a, p. 38).

Yes, "strongly felt" is perhaps one of the main features added by the public dimension. But it does not mean "positively strongly felt," Even more, it does not mean "always strongly felt." On the other hand, the fact that "the others are implicated or witness to the feeling" does not mean that this feeling is necessarily one of pride, as a "natural" consequence of gestures of praise. Actually, the public dimension adds complexity to the recognition experience. In many situations, the experience of being recognized in front of others could be more intensively lived. It follows that social recognition in professional, sports, academic, etc., fields is usually made in public. Nevertheless, in the dimension of lived experience this condition of publicity could cause negative feelings. This could be the situation of one single student praised in front of his or her class. Furthermore, the negative feeling could change depending on who the public is in every situation. For example, in this student's case his/her feelings of embarrassment and humiliation in front of fellow classmates could transform into feelings of pride in front of his/her own parents. On the other hand, recognition received in a private context could acquire tremendous value for a child or young person because of the complicity established with the meaningful educator. Do you remember praise whispered by your favourite teacher that filled you with joy? Do you remember the lasting effect of an approving look and a smile that evaluated your work? Although there were "others" close to you, it did not matter to you. These private experiences of recognition bring out the figure of the educator as central.

However, it is not always possible to live recognition in public. Our students, sons and 
daughters could be misrecognized or even disregarded. Here are some situations:

-Alex has participated in a collective mural and his teacher has congratulated him on a drawing that he has not done.

-Albert has been awarded with a high mark for his good "memory" when remembering certain historical data, but he knows that he has relied on luck and accidentally has got the answer right.

-The teacher has asked for an answer to the problem. Michelle knows it, but she does not dare to say it and only whispers it. Janet has heard Michelle and says the answer loudly. The teacher praises Janet for having understood such a difficult problem.

These situations of misrecognition could be witnessed by others adding ambiguity to the experience. The rest are witnesses. They could testify to the value of this gesture of misrecognition. If Alex, Albert or Janet believes that somebody else knows the facts or even if there is just this possibility, they are not going to feel recognition. I remember here one of the meanings of recognition: "to perceive as existing or true" (Dictionary.com, retrieved April 13, 2009). Children and youngsters perceive this underlying difference between true and false at the moment of recognition. They feel misrecognized, especially if there are witnesses to the situation. By contrast, these aforementioned experiences could adopt another tone if they occur in private. Here the clarification of the mistake depends on the learner's honesty. But, it is still a misrecognition experience.

Perhaps, the most common way children and youngsters are at risk of being misrecognized is different, as exemplified below:

-Caroline has taken pains to finish a drawing required by her teacher. She does not have a gift for drawing. The teacher says that she has to repeat it because she is not going to accept "that" drawing. Caroline feels desolate: she knows that she cannot do it better. Even more: she fears that her second attempt is not going to be as good as the first.

-The teacher has said to the whole class that Martin has very little interest in learning. Actually, the boy is intelligent and curious. He would like to participate more, but his shyness paralyzes him.

-The teacher has organized a play: everybody has a role: actors, actresses, set designers, etc. When classes finished there was quite a hubbub at the hall of the school as the children announced this news to their parents. Only John slips quietly away: the teacher has forgotten him but he did not dare to speak up. This is not the first time that this has happened.

These adults misrecognize their students. It is not difficult to imagine the feelings of unfairness, uncertainty, embarrassment... The fact that these situations would be public intensifies the negativity of the experience. This is very different from the situations lived by Alex, Janet and Albert: the classmates acting as witnesses could reduce their misrecognition. Misrecognition as false recognition seems easier to overcome affectively when it is experienced in front of others. However, misrecognition as true not-knowing from the educator is more difficult to digest, especially in front of witnesses. By contrast, without an audience the tone of this moment will depend on the type of relationship maintained with the educator. Furthermore, 
being misrecognized could be very different to a child who is positively recognized by other significant adults than to a child who does not have other support. When this is the case, misrecognition from an educator could become self-misrecognition. Who does not know people that seem to be blind to their own capabilities and worth? Misrecognition has lasting signs.

Non-recognition or disregard is an extreme of the continuum. Evidently, this is not a pedagogical practice. Unfortunately though, it is a possible experience for our children and youngsters - an experience that any of us could prompt. Non-recognition in a passive form seems so common when dealing with some children: no words, no gestures and looks, no actions... Nothing in particular. This is non-recognition. But, there is an active form of non-recognition, too. Gestures, looks, words directed to scorn what a student has done or said or to reject his/her identity. Sometimes a paradoxical way of recognition could be made to stress the uniqueness of a child in a negative sense. This may be an everyday experience for students with some kind of disadvantage, as Henriksson (2008, p. 144) points out. Passive non-recognition supposes the other's presence: a student who feels his identity is anonymous for his/her teacher. The others' presence could stress the negative feelings but not necessarily. By contrast, active nonrecognition lived with witnesses affects them deeply.

In all these situations of recognition, mis-recognition, or non-recognition, the public has an effect depending on who they are, what the relationship with the child/youngster is, and the kind of knowledge that they have about who is being recognized.

The "power" that is given to us by children and young people is real. Any educator who reflects on the visible and immediate effects of his or her words and actions offered as recognition might confirm the importance of this power. This pedagogical influence may be used to reveal and to stimulate the hidden resources that everybody has. Giving recognition is helping to give the full value to a child. What am I, as a teacher, doing with this tremendous responsibility?

\section{When Recognition gets Adulterated}

These previous distinctions lead us a step further towards the nature of pedagogical recognition. Giving recognition in the context of a pedagogical relation does not suppose pedagogical quality. Actually, it is easy to give "false recognition" or to transform a potentially pedagogic situation into something else. There is the real possibility of "acting” instead of "offering” pedagogical recognition.

Although teachers and parents are permanently asked to give recognition, and although they continuously try to answer these requests, to offer recognition could be frequently just a declaration. For this reason, it is necessary to uncover this false appearance. Despite the fact that this phenomenon seems so common and simple, it is very complex and sometimes ambiguous. In fact, as educators we may think we are giving recognition but our actions may not fulfill its pedagogical conditions.

It is not difficult to see how recognition loses its essence if used by educators as a means to another end. The practice of recognition, especially if it's given as praise, could even lead to actions and situations that are radically opposed to our pedagogical intentions. For example, there is the danger of it being used as blackmail (sometimes emotional blackmail) if the adult uses recognition to obtain some kind of personal benefit. It could turn into flattery if the adult uses it to gain the child's attachment purely for his or her personal satisfaction or self-esteem. In an unconscious way, recognition (like praise, prizes, marks, etc.) may become a refined form of 
abuse if the educator employs it with a certain child in order to highlight the inadequacies of the rest of the class... Of course, all these situations may arise unintentionally. There is therefore a need for "reflective awareness of our pedagogical intentions." Otherwise, we can easily find ourselves saying things like "Look! X was the only student who did it right... You should learn from him/her!"

Pedagogical nature is lost when it is conceived and used as a means to another, not essentially pedagogical, end. Pedagogy only refers to those types of actions or interactions that are intentionally established (though not always deliberately or consciously) by an adult and a child or young person, which are aimed at educational or positive developments in the child (van Manen, 1998).

\section{Doing and Being}

When remembering recognition experiences it seems that those that stand out are the ones where children/young people have reached certain objectives or have fulfilled certain tasks. . Also, we distinguish that the personal effort to do something well or correctly is the key element in experiences where recognition has been received, given or witnessed. Speaking in pedagogical terms, it is not possible to recognize lack of effort.

However, does this fact lead to the conclusion that effort, or the thing achieved, or both are the main reasons to recognize a child/young person? Should these considerations be the most significant for educators? Furthermore, is this emphasis on doing compatible with the attempt to recognize the being of children/young people? This seems to be a contradiction (especially considering the aforementioned reflections). What is the place of doing in recognition?

During the first months of this school year, Paul had been having problems with almost all of the subjects he'd been learning. I was worried about him. One day I realized that Paul's handwriting was a bit neater, and I congratulated him. I played a joke and suggested that it was not his own handwriting. I said: "There is no way that you did that!" and he defended himself by saying: "Miss: it's true, I wrote it myself!" The other children in this class (a convinced chorus) defended him: "Yes, Miss: he did it!"

Actually, Paul himself was surprised with the way his work had turned out because he seemed to be used to doing everything wrong... After, when I spoke with him more seriously, he did not seem to believe what he had achieved. I looked at his face and I felt that he was thinking that he could do things well after all! He was very happy. What a wonderful expression! "I am glad to at least have managed to get one thing right," he was silently saying to us. (A third grade Teacher)

This child has made an effort and his teacher recognizes it. He has done a "good thing." She uses exaggeration to emphasize the value of the child's achievement. Thus, she offers a new perspective of this child's work ("perhaps, another person did it"). It seems that for this child, handwriting has acquired a new value; he feels that his handwriting reflects himself. For his selfconcept, this is a transformational expanding event. It is possible to imagine how this change about what he did has altered his vision about who he is: "This is good," "this was done by me," 
"I am good, too." How does it happen? What does it mean? What is the link between the being and the doing (disclosed in every experience of recognition)?

Indeed, this handwriting was produced with attention, effort, interest, patience. This child was in his handwriting. The entire person "is contained in every fully concrete act" (Scheler, 1973, p. 385). Effectively, “every concrete act always contains inner and outer perception, livedbody consciousness, loving and hating, feeling and preferring, willing and not willing, judging, remembering, representing, etc. (...) It is the person himself, living in each of his acts, who permeates every act with his peculiar character (...) The only and exclusive kind of givenness of the person is his execution of acts" (pp. 386-387). This boy permeated every line of this "simple" handwriting. He is the author. His singular identity permeates his school task.

Even more, "it is through this execution of acts that the person experiences himself at the same time" (p. 387). Thus, in the execution of this task this child not only gave himself up to the others and the world's things but also experienced himself. In this case, he experienced himself as being capable of doing such a good thing. He realized that thanks to his effort, he had managed to beat a difficulty that "characterized" him before this event. He is no longer "the child with learning difficulties who does everything wrong." He has realized that he is a person capable of transforming his own life. This learning is, conversely, transformative of his self: "I am a person who is not always the 'same'; I am a person in transformation with real possibilities to be 'better' and 'more' than what I am presently." Recognition of his handwriting, in this sensitive situation, means recognition of his very being.

Perhaps I believe that I know my student, son, or daughter. I recognize his or her face; I know his or her way of speaking, moving, smiling; maybe, I know his or her preferences, his or her abilities, his or her practical difficulties. Nevertheless, does this person stand out in my consciousness as a singular person? Why not? Does this child or young person feel that my prior concern is his or her being? Perhaps I should re-turn and try to re-know them from the personal perspective. To re-cognize.

Therefore, the recognition of the actions of children/youngsters always supposes recognition of their persons, recognition of their subjectivity. Observing a person's actions can lead us to know them (Wojtyla, 1979). When it is known what a boy/girl or a young person has done, he/she is recognized. Recognition does not occur in a vacuum; it is not a superficial practice, a simple ritual. In the first stages of life recognition on the part of others is crucial.

As teachers, we have a delicate role - to be the privileged witnesses of this wonderful experience of the self's transformation. More importantly, we are particularly responsible when it concerns children's and young people's self. Thanks to recognition, we are strengthening this human auto-determination movement in a pedagogical way. We are recognizing "being" in "doing." This is our truly pedagogical commitment at school and at home when we are dealing with handwriting, reports, exams, lessons, tasks, and so on.

This teacher praised Paul for writing “a bit” better. Perhaps, we could ask, is this not significant enough to be recognized? This does not seem to be the teacher's perception. Neither does the child's experience seem to be insignificant. What is the importance of this fact? Although the achievement may seem "minimal" or apparently simple, it seems that there is a real reason to recognize it. This is the first time that this child has managed to write better and it is not an accidental fact. Paul has done his best.

Evaluating a thing as "the best" depends on the knowledge we have of this person. Is the object of recognition always this "best”? Is it the reason for recognizing? Moreover, do they need to do something right or good to be recognized? 


\section{The Good, the Bad...}

Yesterday, when the afternoon turned to dusk, Judy opened the door that led to her room. She had been painting all day. She wanted to finish a still life.

She called me to look at her picture: some carrots, a cauliflower, and a few radishes on a white cardboard. I was impressed by the vividness of the colors and a certain grade of perfection in the details. But the position of the figures was not the most suitable: rigidness. The painting of vegetables had a strange effect. Nevertheless, I liked it.

I saw her messy place of work; I imagined her painting all the day. Judy is not a perfectionist. Sometimes, finishing something well is a challenge for her. I thought: "although she likes painting, this picture means a significant effort." Touching her shoulder I said cheerfully to her: "Judy, that's fine!" and I praised the natural effect of this painting. Unexpectedly, she reproached me in a disappointed tone: "You always say that everything is 'all right." "My smile transformed into an ambiguous expression. I did not know what to say. (A personal experience as a painting teacher)

This girl's words have originated a stream of questions in my mind: Is it true? Why did she say that? I believed that I was sincere... What is the problem? Am I not truly offering recognition? Am I uncritical with my student's performance? Why? She feels that I give trivial compliments...So, what is the value of my words? She is a learner and her work is not always good, how can I appreciate it? I didn't want to recognize her outcomes; I just wanted to recognize her effort... Why has she reacted in this way? In this experience I felt uncomfortable and clumsy.

However, this situation was an incentive for the self-questioning of my pedagogical coherence. More importantly, this personal conflict vividly revealed to me the intimate relationship between recognition and the capability of recognizing the value of things. This girl poses my evaluation in question. These are answers that I need to find for myself. At the same time, I understand that she is requesting clear guidance about what is good and what is not so good. Not everything can be "all right!” This is an ambiguous or superficial attitude that I should not maintain as an educator. But, is this distinction between right and wrong really central?

Judy is asking me to make this distinction. She is requesting true recognition of her performance. Recognition is centered on human action. Pedagogically speaking, to recognize our students' performance means to distinguish and to approve what is right. However, this rightness extends to some different dimensions. Firstly, it supposes an identification of children's/youngster's capabilities. If what Judy was capable of doing corresponds to her possibilities, it is right. Furthermore, this right which must be accomplished by students means that student's work has to reach some objective qualities. For example, the outlines of the word "mother" must be the outlines of this word, and not another thing; the result of a mathematical problem usually is one; a historical date or a geographical name are not ambiguous terms. The student's answers must be correct to be recognized. In addition, there is a third sense of rightness: the ethical nature of education implies that we have to distinguish the goodness of their actions. Evidently, this goodness belongs to my own values system. Recognition emphasizes the normative complexity of our pedagogical lives. We would not take for granted the goodness of our ethical distinctions. 
In the pedagogical sphere, the human need for recognition gains great value. Children and youngsters who depend on our pedagogical responsibility are indeterminate beings that need a point of reference in order to learn the worth of almost everything: themselves, others, what they do and the world they live in. As Langeveld (1983, para.1) says, "humans are not simply born; they do not just grow up into mature adults. For what we call a child is a being that calls to be educated."

Like Judy, they need to know the value of what they do. However, what is the "real" value of the performance, work, actions, etc., that we daily examine? How do we determine it? This is one of the great dilemmas of teaching practice. The extensive discussion about the school evaluation system and criteria is an open wound. Possibly, at the level of daily concerns just one answer could be given: there are no easy answers. Actually, in concrete pedagogical situations it is necessary to rely on the educator's judgment. This tremendous confidence demands pedagogical honesty. This pedagogical honesty could be translated as a genuine commitment to be a thoughtful teacher, counsellor, mother, for example. In this sense, disclosing the essential nature of recognition is an important and key question.

Recognition has condensed normative significance. Recognition is at the heart of pedagogy "which, by definition (...) distinguishes what is good or most appropriate from what is bad or inappropriate for this child or those children in particular circumstances" (van Manen, 1995, p. 35). Put simply, people tend to show recognition for the things they themselves conceive as "good" or "right." Behind what a person does, says, or leaves out, there is an ethical positioning which is pathically expressed. Feelings and moods speak about and come into contact with things in our world. Enthusiasm, happiness, motivation towards the world show that some things are "good," "suitable," "worthy," "nice.” Conversely, rejection, indifference, aversion, distrust, etc., show that some things are "bad," "inappropriate," "worthless," Feelings and affective positioning are contagious. Moreover, this contagious phenomenon becomes strong when the adult possesses pedagogical authority.

In addition, concrete and everyday experiences of recognition, especially at school, manifest that our gestures, looks, words, silences, etc., not only guide an individual child or youngster but also the rest of the group in terms of what is "good" and what is "right." Educators should take care of the ethical atmosphere that is being created among children in any instance of pedagogical recognition.

The normative significance of recognition calls teachers to pay attention to their ethical personality expressed in practice. It is necessary to examine closely what, how, when, and, particularly, why one recognizes. In other words, the exercise of critical awareness is important: As educators we are frequently saying what is good and what is not good to a lot of people: Am I aware of this fact? What are the values that I would like to share with them? What are my reasons for calling this thing "good" or "worthy"? Besides this reflective attitude, it would be useful for our critical awareness "to listen" to what children and young people ask: "Why are you laughing...?” "Why did you say that to us...?" "Why is it no good...?” "The other day you told us..., and now you aren't doing it...!” The possibility of developing an active critical conscience about ethical concerns depends on our ability "to listen," an ability which is especially needed in our pedagogical lives.

Ultimately, the responsibility of adopting the pedagogical practice of recognition entails the aspiration of being a good educator. Hansen (2001) states: "to teach well implies, at one and at the same time, cultivating a moral sensibility, enlarging one's person, and enriching one's conduct. That posture calls to mind the familiar notion that teachers need to be lifelong learners" (p. 40). The practice of recognition entails this attitude of lifelong learners ready to learn from 
every situation lived with children and young people. Children are excellent, demanding teachers.

\section{The Value of Everything}

Educators may constitute guides in the very experience of recognition. It is common for children and young people (like adults) to only consider results to have a value, rather than the effort or the meaning behind the tasks. Moreover, there is a common and secret bias to consider that the only things that are worthy of recognition are those that are extraordinary or outstanding. Only these things make us offer praise and laudations. We may not be conscious of this choice, but this prejudice does arise frequently in the way we recognize. "What a fast student!" is not the same as "What great work!" Normally, we like rapidity and efficiency. But, what about the slow child? Recognizing outstanding, striking, commonly valued things means, in contrast, ignoring the opposite. How many children go for too long without being acknowledged for anything right or good just because what they do seems ordinary?

Here the influence of teachers is especially important and may change perceptions and values. Ultimately, it is "understandable" that results are not the most important thing. It may be understood that any outstanding achievement lacking effort or merit is not worthy of recognition in itself. In addition, it may be understood that certain achievements may be "right" for one child but not for another. In this sense, Hansen (1995, p. 76) explains how a pedagogical situation may be "successful" for certain students and teachers in their particular circumstances. Children and young people also understand this if they rely on our help. The adult's responsibility is required to function actively to widen the horizons of meaning and value in the children and young people's world.

Every minute of effort is significant if it is all we can do at this early stage of our life, and this is even more the case when that seems to be the only good thing that a child/young person is able to do. Paul's sensitive teacher was able to notice that there was an opportunity to recognize his student.

Furthermore, is an effort "just” an effort? I clearly remember my student-teacher supervisor for her way of recognizing the small and everyday achievements of each one of us. This teacher's recognition gestures acquired an unusual value and suitability in a context where everything was little and, at the same time, full of life and importance: a class of four-year-old children. Beyond this context of childhood, learning and maturing are accomplished by a continuum of little things. In consequence, minimal achievements may offer an appropriate opportunity to give recognition. Sometimes, these little achievements are so "minimal" and have been reached, largely, thanks to the educator's help. Nevertheless, this does not diminish their value.

\section{Recognition Needs Pedagogical Authority}

- "Well, have all of you finished already?”

- "Yes, Sir."

- "Well, so...Let's look...everyone will show their work."

- "Well, whose work are we going to check now? Marie's?"

- "Yes,” says Marie. 
"Let's have a look... What do you think about it?"

- “Good,” says a girl.

- "It is not good,” says Jojo.

- "Is it not good?" the teacher repeats and asks at the same time.

- "It is much (sic) fine," says Marie, the author, defending herself. She had written

all of the letters completely and clearly, but they were in the wrong place and tended to go down (the sheet of paper did not have lines).

- "Is it 'much' fine?" the teacher repeats, stating and asking at the same time.

- "Yes...but, [what happened to] the word 'mom'?" asks another girl.

- "Can we read the word 'mom'?!” the teacher says emphatically.

- "Yes, but...down!” a girl answers immediately.

- "No," answers a boy at the same time.

- "Because she went up a bit, but then she turned downwards," says the teacher in a convincing tone. While he speaks, Marie gazes at him with an indescribable look: she seems to be seeking his support; she seems to be uncertain about the other children's opinions of her handwriting. As soon as Jojo said, "It is wrong," Marie started looking for "something" on her teacher's face.

- "But, I believe it isn't bad... Is it?" the teacher finishes. (A scene from Etre at Avoit, 2002)

Since children and young people have their personal evaluation of their performances and their own conclusions about the rightness or wrongness of behaviours, tasks, attitudes, etc., the adult must realize that they "are not always right." It is frequent to experience situations where a child thinks: "it is wrong” to evaluate another child's work but we do not share this perception. It is even possible for a child to be unaware or sceptical about the worth of his or her performance. The educator, by virtue of his or her authority and influence, helps him or her to accomplish a real evaluation of it.

The teacher has to be critical in order to meet the demands of pedagogical recognition. This critical attitude is rooted in pedagogical authority. The present day educational context poses problems for the practice of authority (van Manen, 1998). How are these aspects of pedagogical authority reflected in everyday actions involving adults and children? Many specific examples easily spring to mind. It is the specific situation of recognition that I have to consider. In the former account, the teacher would not have to resign to his perception of Marie's handwriting.

He is exercising his authority to preserve the true worth of Marie's work. He would not have to let himself be influenced by his children's perceptions in this circumstance of pedagogical recognition, especially because he has realized what a vulnerable situation this is for Marie. This experience shows how recognition needs authority to be pedagogical.

In the first anecdote in this paper, I described my own perplexity when faced by a teenager that I did not know how to recognize. I asked myself: "Is my recognition appropriate because that person feels personally recognized? Should an educator's recognition depend on their student's perception of his or her work?" Significant recognition situations lead one to understand that when an adult recognizes, he does not necessarily have to confirm the child or young person's perception about his or her performance or of himself or herself. Instead, and this is the main reason, educators necessarily give confirmation or rejection about the real rightness or wrongness of things and actions.

This is not a denial of a child's personal point of view and values but a confirmation of his or her needs. Thus, the adult view supports the development of these values. An educator's view is 
always more expert than a child or young person's view. Moreover, the educator is a "childwatcher who guards and keeps in view the total existence of the developing child" (van Manen, 2002a, p. 26). Therefore, in specific and potentially pedagogical situations, pedagogical views of educators offer the possibility of a valuable gesture of recognition.

\section{Recognition in Action}

\section{Recognition Involves Pedagogical Tact}

After the first lesson, she had been painting many hours. This morning I went to her room to look at her work. I was uncertain: "Should I be indifferent - without emotion - when I look at her painting? Is that what she wants? No, the idea is to help her and tell her my real opinion," I decided.

Here I am, observing her chromatic circle and other color proofs. It is her first contact with painting and it fills me with happiness, but, she obviously has little control over the material. I cannot congratulate her. I see a bit of embarrassment on her face. It is only too clear that she would not be happy. At this moment I remember that she told me a few days ago: "I want you to tell me the truth because I want to learn." I tell myself that I should control my words. I try to look moderate and say: "It is not bad..." (In spite of my real joy!). But I could not help but say: "Watercolor is one of the most difficult techniques. It is fine!" But, she seems not to hear my words... She explains to me nervously how difficult it is to control the proportion of water, to imitate natural colors. She seems a bit ashamed of her results. I would like to motivate her, but my words become silence. I just encourage her (shyly) to try again. Just now, it seems to me that she needs me to recognize her effort. But, I should not exaggerate! Once again, I feel that the problem is in my face: I try to keep it somewhere between "serious" and "understanding". I change the conversation and speak about the names of the colors, how to clean the paintbrushes, the type of card, etc... The awkward moment has passed! (A personal experience as a painting teacher)

In this situation, I discover that my facial language is worthy of special attention. Unavoidably: my facial expression, though a subtle and involuntary gesture, is disclosed in my evaluation. My face is my evaluation. One's face is a powerful means for manifesting recognition. Perhaps, it is the most powerful means. Conversely, it can be employed to refuse recognition to someone. Many times, it could be an unwitting action. To learn the grammar of our facial language could help us to prevent it from betraying us at an unexpected moment. Nevertheless, the grammar of my face serves to reflect the speech of my heart and mind. How I look at this child means What I think and feel about him/her.

I should not forget that "the face speaks" (Levinas, 1969, p. 66 quoted in Waldenfels, 2002, p. 67). My face is speaking inevitably and permanently. It is sometimes hard to erase the impact of the look of disappointment on an educator's face, especially if it has been an unfair gesture. Who doesn't remember this kind of experience?

In addition, it is hard to deceive with one's face, especially with children and young people. So, how do I teach my face the pedagogical grammar (to be more attentive as an educator)? A 
superficial adult attitude may be a hurtful and clear manifestation of misrecognition in so many situations. This was what little Edith, characterized for being a smart girl, experienced with her family:

Out of school my behavior was more and more silent and quiet, and this attracted the attention of my family. Perhaps it was because I was immersed in my inner world. Or perhaps it was the disdainful way adults used to deal with children. When I started speaking about things I seemed too young to speak about, they laughed and spoke of it as if it were a curiosity. For this reason, I preferred to stay in silence. ("Vivimos para servir. La juventud de Edith Stein," 2005, p. 31)

This little girl feels that her person is not being appreciated. She is misrecognized. She is a singular (intelligent, profound, sensitive...) person. She is not like any child; she is a unique person. Why do these adults think she is a "strange" child? Since the moment they have made a comparison, they are not being respectful to her. Genuine recognition is respectful of the child. It is never given in an ironic tone. In fact, she feels that she is not unrecognized. This disdainful way of receiving her words and actions give them a negative value.

I could criticize those adults for being so thoughtless. Nevertheless, it is possible that my words have a negative effect on a child or youngster too. I need to think why. I need to look at his or her face. A thoughtful educator takes into account the way a child welcomes their gesture of recognition. A condition that makes genuine recognition possible is to pay careful attention to children's and young people's faces. Perhaps, this attentive look will lead us to experience the call of this person. Being looked upon by this face means experiencing it as an order, as if somebody superior was speaking to me. The face of the other (especially this young face) is the poor person for whom I could do everything and for whom I must do everything. It is I who must try to find all the resources to respond to this call (cf. Levinas, 1991). This face is asking for my recognition. Will I deny its request?

It is simply unavoidable: A careful look brings a careful action. Do not draw too much attention to a shy child, do not neglect a child who has feelings of incompetence, do not make unfair distinctions with a difficult child; avoid over-praising a child's "excellence" in some situations... Careful actions mean being considerate to everyone. Consequently, the main question should be: how does this child/young person experience this recognition in this situation (van Manen, 2002a)?

Again little Edith may show us that children and young people could live a very different experience from what adults believe is "recognition":

My whole family described me from very early on as especially having two qualities. They reproached me for being ambitious (with reason) and they emphatically called me "smart Edith". Both things hurt me a lot. The latter because I understood that they thought I believed it myself. Moreover, it seems to me that they meant that I was only smart. However, I had known since very early on in my life that it was more important to be kind than to be smart. ("Vivimos para servir. La juventud de Edith Stein,” 2005, p. 22) 


\section{Ways of Recognition}

Is there one essential way of recognizing everybody? Is there a way that is always well accepted? When I attempt to answer these questions by going back to my own past recognition experiences, I acknowledge that the essential condition is one which offers personal availability. When a teacher or parent is able to be there for a child, that is to be completely available to him or her, he or she cannot help but offer recognition. Of course, the amount of time does not matter. Availability is intimately linked to listening. Thus, the main concern is to be able to listen to children and, therefore, to have the "experience of the Thou," as Gadamer (2004) suggests:

In human relations the important thing is (...) to experience the Thou truly as a Thou - i.e., not to overlook his claim but to let him really say something to us. Here is where openness belongs. But ultimately this openness does not exist only for the person who speaks; rather, anyone who listens is fundamentally open. Without such openness to one another there is no genuine human bond. Belonging together always also means being able to listen to one another. (p. 355)

To experience the Thou truly as a Thou, let him really say something to us. Let this child or this young person really say something to us. Let them say what they want, what they think, what they are. We need to learn to listen. We need to learn to let them really say something to us and recognize that what they say is an intimate expression of who they are. In this sense, an effective antidote to the pedagogical practice of recognition may be "not having time to attend to small things."

Small, special, common, daily forms of recognizing. What is the essential core of this variety? At the heart of pedagogical recognition there seems to reside a sincere esteem for the small but continuous efforts made by children to learn and to grow up - a sincere esteem for the uniqueness of every person disclosed through their actions. Small everyday advances are reason enough to be recognized.

However, there is a need to avoid falling into the traps of monotony or empty recognition. If recognition becomes routine, it could lose its meaning. A compliment "should be meaningful and should not be granted indiscriminately because, if given too readily and too freely, it may lose its significance" (van Manen, 2002a, p. 35). However, I think that some academic routines make children and young people feel recognized. Who does not remember an affectionate greeting or sincere praise received from his or her favorite teacher? (I remember the typical "surprise" with which my father used to recognize the important achievements of my childhood. What wonderful and lasting moments!) Even though these actions could be expected, they are really appreciated. In other words, if we have found suitable and pedagogical forms of recognition, why don't we adopt them as daily practices? Indeed, certain routines are necessary to make sure that everyone has the opportunity to receive recognition, but without it becoming routine!

Recognition has to be tangible but not in a material sense. It means that an educator should not always resort to such things as gifts, prizes, good grades, etc. Although things like this might be welcomed, other forms of recognition are more appreciated and more necessary. They are always welcome gestures, even though they have been received a lot of times. Actually, recalling personal experiences, one could notice that material and personal forms of recognition have different effects. A simple gesture of pleasure, a thoughtful way of receiving a piece of work, a trusting smile, and many similar details have lasting effect. Furthermore, pedagogical recognition is always truthful. Although an adult could use exaggeration to amplify the effect of the child's 
achievement, recognition should not be confused with simulation.

Recognition is intertwined with personal identity, and "self-identity is the realization of the tension between the being of self and the becoming of self, between who we are and who and what we might become" (van Manen, 2002a, p. 38). As a teacher, I observe that a practical way to promote this realization (and to reduce the distance between the being and the becoming of self) is to give responsibility. This is the way that children and young people are able to show what they are able to do and, consequently, who they are. When an educator gives responsibilities and opportunities as means of recognition, what they are actually giving to children and young people is a great source of new occasions for being recognized.

\section{Being Recognition}

So, what is the reality? Are all our children being recognized? Are all the students in my class being recognized? We see that every child and every young person needs recognition. But, how can a teacher with many children satisfy this demand? Is it an unrealistic purpose?

The possible answer is extremely simple and compromised at the same time. When an educator incarnates recognition, that is, when recognition belongs to his or her pedagogical being, there is no necessity for extraordinary conditions. Every condition can be suitable: a large group, a little but very complex one, a single "difficult" child... Fulfilling this primordial condition, minimal gestures are effective without considering the quantity of personal contact, resource availability, school schedule, and even one's personal qualities or limitations.

Actually, giving recognition to everybody is hard and tiring: Who is able to assume such a task? Embodying recognition - being recognition - seems not so difficult. Being recognition does not seem so inaccessible. We are talking about a person who acts, speaks, moves, smiles, etc., communicating this attribute. Ultimately, I am dealing with the question of the embodied language of our being. In particular, facial language is a powerful means for reaching everybody. It could take just a few seconds...And the educator has given recognition and reached a little person who was waiting for it!

A simple look could say: "I know who you are"... "I accept you”..."I appreciate you." Giving genuine recognition ultimately means recognizing who the person is that is face-to-face with him or her at that moment. Is this a matter of school resources? Is this a problem of "lack of time?” Perhaps so (Who doesn't need time?!), but it is not the essence. Translating recognition from doing to being implies changing our perspective. Paradoxically, giving recognition is easier than being recognition.

Recognition is not a completely spontaneous gesture. When it seems spontaneous, it is because the adult has been predisposed to find the occasion. He or she is always waiting for the exact moment in which he or she can offer a timely word. Thinking about her past experience, Paul's teacher (the child who improved his handwriting) writes:

I chose him to be my "teacher's aide". This responsibility meant that he had to write some notes on the blackboard or on some paper if I needed it done. This was a spontaneous decision. I had always had this child in mind: "What a shame! He does not seem to learn properly...”

Tact seems characterized by moral intuitiveness: "A tactful teacher seems to have the ability of instantly sensing what is the appropriate, right or good thing to do on the basis of perceptive 
pedagogical understanding of children's individual nature and circumstances” (van Manen, 1995, p. 45). This spontaneous decision was born in the warm bonfire of thoughtful reflection: "I had always had this child in mind," she explains sincerely. She was frequently thinking how to help him. This reflective exercise is like a force that sculpts who I am. It prepares me for action. An educator needs to cultivate pedagogical thoughtfulness and tact.

Children and youngsters have the opportunity to experience recognition when this recognition belongs to an educator's being. I remember that teacher who impressed me a lot: she was something like the incarnation of pedagogical recognition. She was recognition. I imagine that this exercise of thoughtful recognition, delivered day by day, had transformed her. Recognition and being are clearly intertwined.

\section{The Butterfly Effect}

I asked many students to solve math exercises at the blackboard. Then, I asked a child who always has problems doing calculations. He came to the blackboard frowning as if he were angry. He looked worried with his shoulders drooping and his head hanging low. I thought "what's going on?"

He obtained the correct answer with my help. Then, I said to him warmly: "Mark, that's right!" He smiled, and the rest of the class clapped. He went back to his seat. I saw him: He was walking confidently, with his head held high. Happiness and pride. He felt like the rest of the children in the class. He was not an unsuccessful child. When I asked another child to do new exercises, Mark told him: "It's as easy as pie." (A first grade teacher)

Sometimes a teacher's evaluation of a student's work may help them to find personal routes for doing things. As long as the educator strengthens the children's sense of value and singularity, they acquire a sense of self-trust in some tasks that have uncertain results for them. In addition, thanks to recognition, the educator can help to diminish the anxiety that could be experienced by children when faced with complex tasks. In our everyday pedagogical experiences, recognition is a means to balancing the intense experience of failure lived by certain children during their learning process.

The teacher involved in the former experience explains that "by stimulating this positive side, this child may see himself as a child similar to the other children: sometimes he can make mistakes and other times he may have good ideas. He has the same possibilities as the others. If he is sure that he sometimes knows how to do things and can do some things 'well,' a mistake does not mean anything." A child with positive experiences of recognition may manage to perform tasks confidently that he may have considered negative challenges at the beginning.

Unfortunately, the absence of real pedagogical recognition may lead a child to withdraw and hide that which should have been his or her unique contribution from everybody else. I realize that the possibility of being recognized, though only for something small, means the right to be treated with equal esteem and regard. Have I discovered the best, the unique, the noteworthy in every child or young person entrusted to my pedagogical responsibility? Why?

At the core of all experiences of recognition there is one immediate effect on the person. Thanks to a gesture of recognition, the educator touches the inner side of the child/youngster in an effective way. Although we may remember the effects of some past experiences of 
recognition much later in our lives (Jackson, 1992), recognition can immediately leave its mark on a child. This is an invitation not to "wait until tomorrow to give the recognition that you can give today." This is a lesson that experience teaches many educators: as Paul's teacher reflects,

This "little" event was the beginning of a meaningful change in a child who started to feel important to his teachers and classmates. Indeed, the change was centered on his attitude to learning. That day, his handwriting got a bit better, but since that day he made an effort, and he managed to develop very nice handwriting.

One meaningful experience of recognition may constitute an important moment in a child's life. Educators who recognize pedagogically may constitute an important moment in a child's or youngster's life. And they can never tell where their influence stops (Barone, 2001). The gaining of recognition may drive students to perform difficult tasks more confidently and to make important decisions. Recognition outlines the possibilities of identity and ethical personality. It may also mean a personal change in terms of personal worth to others - especially to the educator.

One small event in somebody's life may mark the beginning of a continuum of meaningful transformations... And, day after day, these little events offered by a tactful educator...Educators transform lives forever.

\section{Endnotes}

${ }^{1}$ I use the word "educator" to speak about teachers, fathers, mothers, counselors, etc. In the Spanish context, educator is a person who educates: who is responsible for the development of intellectual, moral, social, physical faculties of children and young people (see "educador" and "educar” in RAE, 2008). Nevertheless, an adult could be teacher, mother, administrator, etc., but not a genuine educator. Thus, in the context of this paper the term "educator" intends to adopt the sense of "pedagogue" that van Manen proposes: "pedagogue is an educator (teacher, counselor, administrator, etc.) who feels addressed by children, who understands children in a caring way, and who has a personal commitment and interest in children's education and their growth toward mature adulthood" (van Manen, 1994, p. 138). Thus, "educator" means good educator or pedagogue, that is, reflects the ethical nature of pedagogical responsibility. Van Manen applies this notion to professionals of teaching, but I extend it to parents. In the Spanish context education simultaneously signifies two English meanings: education (teaching, instruction, and schooling) and upbringing (parental care).

2 This French film has been watched in the version dubbed into Spanish (by Karma Films DL, Madrid: 2004). The translation into English is the responsibility of the author.

${ }^{3}$ recognize (n.d.). Online Etymology Dictionary. Retrieved March 20, 2008, from Dictionary.com website: http://dictionary.reference.com/browse/recognize.

${ }^{4}$ At Dictionary.com (Retrieved April 2, 2009), we find a list of meanings similar to what we can find in the French dictionaries cited by Ricoeur (2005). On the other hand, the Cambridge dictionary online (Learner version, retrieved April 2, 2009) shows only three meanings that match with those stressed by Ricoeur, albeit in a different order. In the Spanish dictionary, the 
range of meanings is similar to the English version cited (Diccionario de la Real Academia de la Lengua Española, retrieved April 2, 2009).

${ }^{5}$ Spiegelberg mentions the influence of Reinach on his students: "Independently of each other, the Göttingen students of phenomenology like Wilhelm Schapp, Dietrich von Hildebrand, Alexander Koyré and Edith Stein, in their accounts of this period refer to Reinach, not to Husserl, as their real teacher in phenomenology" (Spiegelberg, 1994, pp. 191-192). The translation into English of "Vivimos para servir..." is the responsibility of the author.

\section{References}

Ayala, R. (2008). La metodología fenomenológico-hermenéutica de M. van Manen en el campo de la investigación educativa. Posibilidades y primeras experiencias. Revista de Investigación Educativa, 26 (2), 409-430.

Barone, T. (2001). Touching eternity. The enduring outcomes of teaching. New York: Teachers College Press.

Connolly, J. (2007). Charting a course for recognition: A review essay. History of the Human Sciences, 20 (1), 133-144.

Diccionario de la Real Academia Española de la Lengua (RAE). (2008). Retrieved October 1, 2008 and April 2, 2009 from http://buscon.rae.es/draeI/.

Dictionary.com. (2006). Retrieved April 2, 2009 from http://dictionary.reference.com.

Gadamer, H. G. (2004). Truth and method. Second, Revised Edition. London: Continuum.

Hansen, D. (1995). The call to teach. New York: Teachers College Press.

Hansen, D. (2001). Exploring the moral heart of teaching. Toward a teacher's creed. New York: Teachers College Press.

Henriksson, C. (2008). Living away from blessings. School failure as lived experience. Ontario: The Althouse Press.

Jackson, P. W. (1992). Untaught lessons. New York: Teachers College Press.

Langeveld, M. (1983). Reflections on phenomenology and pedagogy. Phenomenology \& Pedagogy, 1 (1), 5-10. Retrieved March 3, 2007, from http://www.phenomenologyonline. com/articles/langeveld5.html

Levinas, E. (1991). Ética e infinito. Madrid: Visor. 
Levinas, E. (2006). Entre nous: Thinking-of-the-Other. (M. Smith \& B. Harshav. Trans.) London: Continuum.

Ricoeur, P. (2005). The course of recognition. (D. Pellauer, Trans.) Cambridge,MA:Harvard UP.

Saeverot, H. (2008). Teacher praise and encouragement: Towards an education for democracy. Phenomenology \& Practice, 2, 49-62.

Sandoz, G. (Producer), Philibert, N. (Director), (2002). Être et Avoir. [Documentary Movie] France: Maïa Productions.

Scheler, M. (1973). Formalism in ethics and non-formal ethics of values. A new attempt toward the foundation of an ethical personalism. (M. Frings \& R. Funk, Trans.). Evanston: Northwestern UP.

Spiegelberg, H. (1994). The phenomenological movement. A historical introduction. Third revised and enlarged edition. Dordrecht: Kluwer Academic Publisher.

Van Manen, M. (1994). Pedagogy, virtue and narrative identity in teaching. Curriculum Inquiry, 4 (2), 135-170.

Van Manen, M. (1995). On the epistemology of reflective practice. Teachers and Teaching: Theory and Practice, 1 (1), 33-50.

Van Manen, M. (1996). The pedagogy of recognition (Research Project Page). Retrieved February 2, 2007 from http://www.phenomenologyonline.com/max/projects/hsrecogn.html

Van Manen, M. (1997). Researching lived experience. Human science for an action sensitive pedagogy (2nd ed.). London, Ontario: Althouse Press.

Van Manen, M. (1998). El tacto en la enseñanza. El significado de la sensibilidad pedagógica. Barcelona: Paidós.

Van Manen, M. (2002a). The tone of teaching. Second edition revised. London, Ontario: The Althouse Press.

Van Manen, M. (2002b). Inquiry: Reductio. Retrieved October 28, 2006, from http://www.phenomenologyonline.com/inquiry/10.html

Vivimos para servir. La juventud de Edith Stein. (2005). Lérida (Spain): Estel-Forja.

Waldenfels, B. (2002). Levinas and the face of the other. In S. Critchley \& R. Bernasconi (Eds.), The Cambridge companion to Levinas (pp. 63-81). Retrieved September 28, 2008, from http://cco.cambridge.org/extract?id=ccol0521662060_CCOL0521662060A004

Wojtyla, K. (1979). The acting person. (A. Potocki, Trans.). In Tymieniecka, A-T. (Ed.), Analecta Husserliana, Vol.X. Dordrecht: Reidel. 